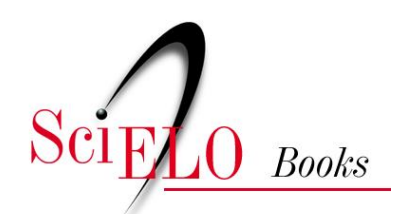

\title{
Experiencias de buenas prácticas \\ 10. La familia asume el uso de las TIC como apoyo al aprendizaje
}

\author{
Silvania Salazar \\ Miriam Gallegos
}

\section{SciELO Books / SciELO Livros / SciELO Libros}

SALAZAR, S., and GALLEGOS, M. La familia asume el uso de las TIC como apoyo al aprendizaje. In: GALLEGOS NAVAS, M., ed. La inclusión de las TIC en la educación de personas con discapacidad: relatos de experiencias [online]. Quito: Editorial Abya-Yala, 2019, pp. 147-155. ISBN: 978-9978-10-495-8. https://doi.org/10.7476/9789978104958.0013.

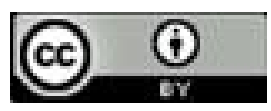

All the contents of this work, except where otherwise noted, is licensed under a Creative Commons Attribution 4.0 $\underline{\text { International license. }}$

Todo o conteúdo deste trabalho, exceto quando houver ressalva, é publicado sob a licença Creative Commons Atribição 4.0.

Todo el contenido de esta obra, excepto donde se indique lo contrario, está bajo licencia de la licencia $\underline{\text { Creative }}$ Commons Reconocimento 4.0. 
Es importante señalar que en el año 2015 el proyecto fue presentado al panel internacional de jurados del concurso de excelencia educativa organizado por la Fundación Para la Integración y Desarrollo de América Latina (FIDAL), dentro del proceso de evaluación el proyecto fue visitado y recibimos la distinción de ser considerados como un proyecto finalista.

\section{Figura 71}

Estudiantes de EINA utilizando el lápiz digital de la pantalla MIMIO

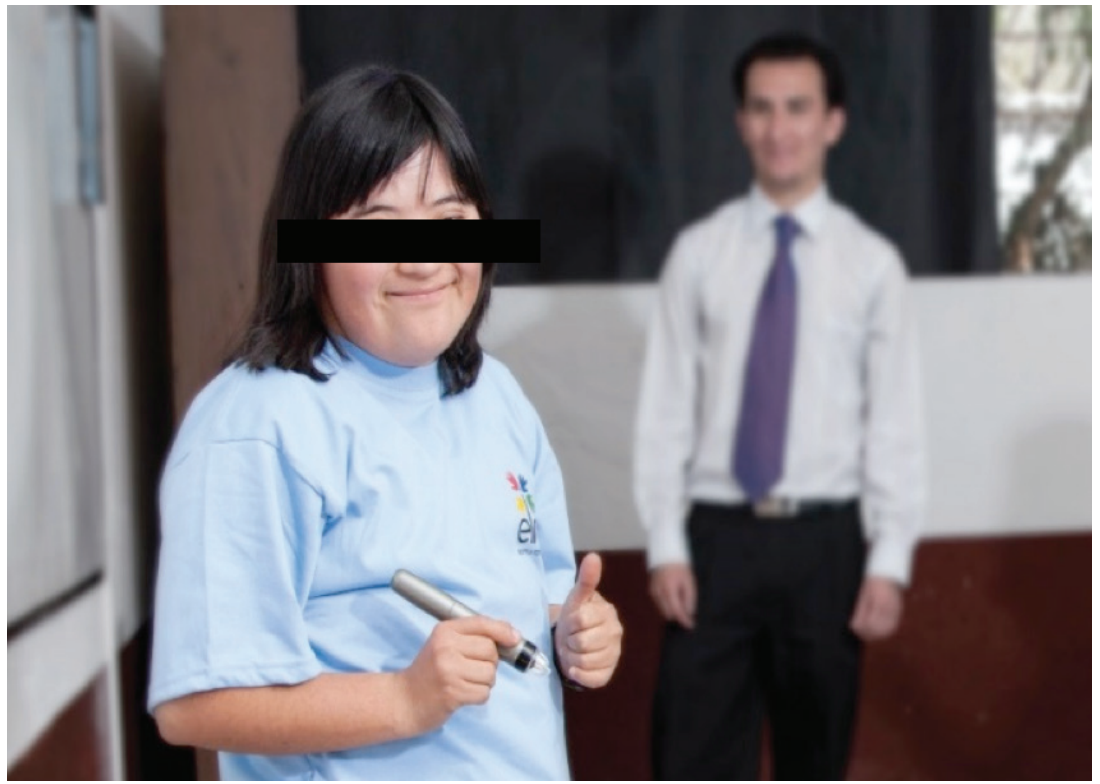

Foto: Daniel Salas (2016)

\section{La familia asume el uso de las TIC como apoyo al aprendizaje}

"Tan solo por la educación puede el hombre llegar a ser hombre. El hombre no es más que lo que la educación hace de él" (Immanuel Kant) 


\section{8}

\section{Ecuador}

Quito

Responsable: Silvania Salazar

Gestores de la práctica: la familia comparte del equipo de apoyo

La presente experiencia constituye un relato de trascendencia ya que involucra el trabajo de apoyo que desarrollan las familias cuando en el seno de ellas existe un miembro con discapacidad, es menester reconocer que la experticia que desarrollan las familias en este caso en particular el deseo de una madre de lograr que su hijo cumpla con los sueños y metas que toda familia para sus hijos se convierte en la motivación para desarrollar un colaborativo con los maestros.

\section{Motivación}

Silvania la protagonista de este testimonio es madre de Jorge Sebastián, quien hoy es un joven de 21 años que tiene una condición de discapacidad intelectual leve a consecuencia de una agenesia del cuerpo calloso (ACC) y al síndrome de Angelman, debido a los apoyos recibidos desde edades tempranas ha superado muchas de sus necesidades personales y de aprendizaje, y actualmente se desempeña como un adulto independiente.

En este proceso, su madre profesora de profesión, asumió el desafío de ser la primera maestra de Sebastián y superar con mucha fuerza el impacto del diagnóstico médico centrado en todas las debilidades y/o problemas que su condición de discapacidad genera, nunca se le informó de todas las fortalezas, y potencialidades que ella descubriría cada momento en su hijo.

Con esta visión centrada en los "problemas del niño" inició el largo camino de las terapias con el objetivo de mejorar los posibles trastornos motores y del aprendizaje que puedan aparecer a lo largo de su desarrollo.

\section{Cuenta Silvania:}

Cuando inicia su proceso educativo desde los 5 años, empiezo a utilizar las TIC, para incentivar en mi hijo el proceso de adaptación a la institución educativa ya que en la Fundación de Enseñanza Individualizada 
149

para Niños, Niñas y Jóvenes con Discapacidad Intelectual (EINA), Escuela el Parvulario y Colegio Ciclo Básico Popular Horizontes utilizan herramientas tecnológicas para apoyar el aprendizaje en los estudiantes con discapacidad intelectual.

Figura 72

Jorge Sebastián de 2 años empieza su proceso de formación

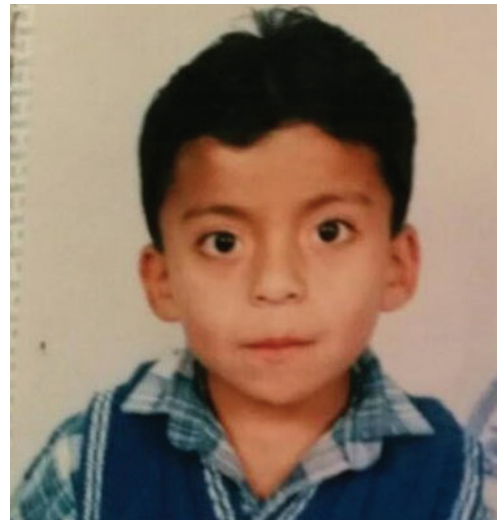

Foto: Silvania Salazar (2016)

Figura 73

Fundación EINA

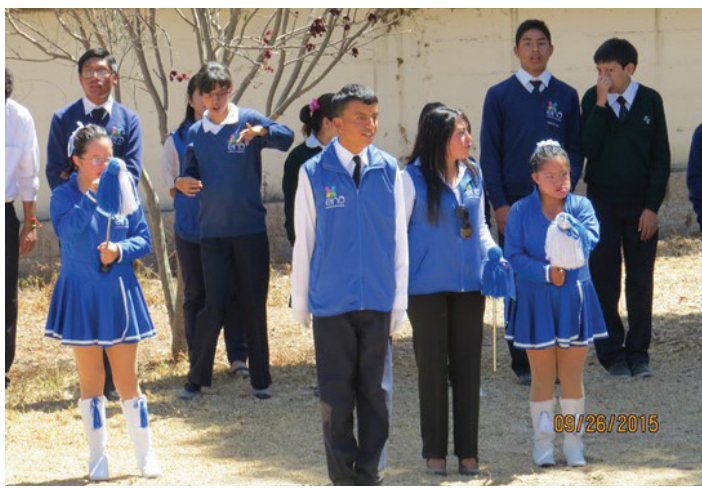

Foto: Silvania Salazar (2016) 
150

Gracias a la experiencia como docente que tiene esta madre relata la experiencia de aprendizaje de su hijo y las describe según las etapas de desarrollo evolutivo planteadas por Piaget, como ella lo manifiesta fueron la guía para desarrollar su trabajo que lo expresa de la siguiente manera:

\section{Etapa sensorio-motriz}

Edad desde el nacimiento hasta 2 años: el desarrollo cognitivo se articula mediante juegos de experimentación, muchas veces involuntarios en un inicio, en los que se asocian ciertas experiencias con interacciones con objetos, personas y animales cercanos.

Durante este período permitía que Sebastián, explore y juegue con varios programas interactivos de la computadora como: Pipo, Colorea 4.0, Nuestro cuerpo, Educapeques, Videos musicales, juegos en las máquinas, entre otras, espacios que le permitían observar figuras, colores y escuchar diversos sonidos.

\section{Etapa pre-operacional}

Edad de 2 a 7 años: empiezan a ganar la capacidad de ponerse en el lugar de los demás, actuar y jugar siguiendo roles ficticios y utilizar objetos de carácter simbólico.

Empecé con enseñarle el equipo de computación en la casa, como funciona para que se vaya adaptando a su uso.

Los programas interactivos fueron de gran ayuda para que asimile y comprenda lo enseñado.

Para mejorar su razonamiento numérico utilice juegos, como el ábaco, agrupar semillas, canicas, diseños de figuras para que coloree indicándole muchos y pocos para desarrollar el proceso matemático. Escuchar cuentos para mejorar su lenguaje y comprensión lectora. 


\section{1}

Figura 74

Jorge Sebastián con los juegos interactivos

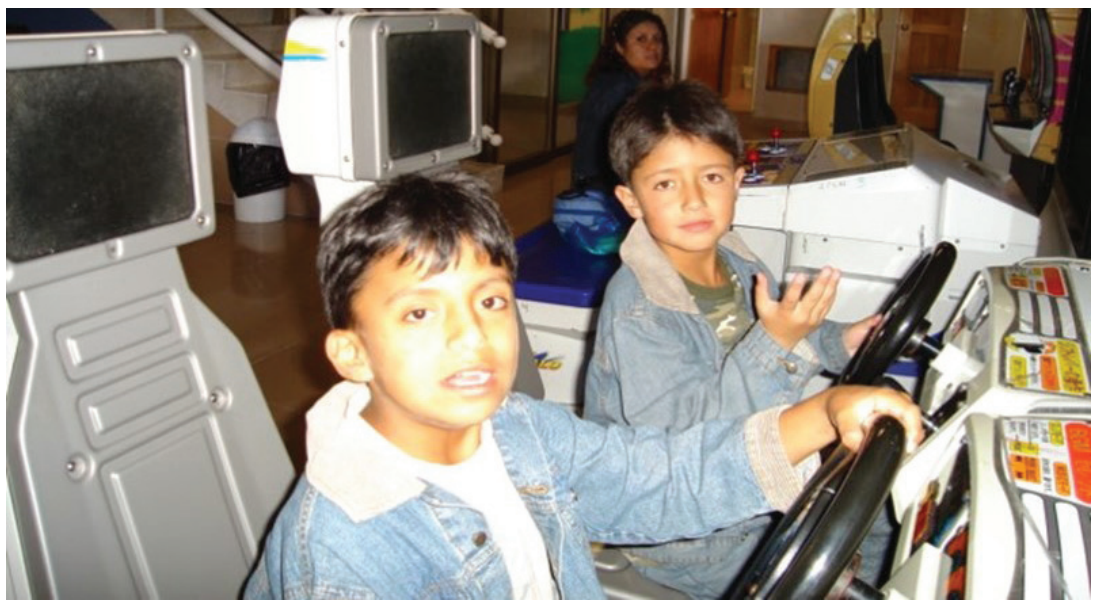

Foto: Silvania Salazar (2016)

\section{Etapa de las operaciones concretas}

Edad de 7 a 12 años: desarrollo cognitivo en el que empieza a usarse la lógica para llegar a conclusiones válidas, siempre y cuando las premisas desde las que se parte tengan que ver con situaciones concretas y no abstractas.

En este período se entrena en varios programas que le permitieron semejanzas, diferencias entre objetos, sopas de letras, crucigramas simples; empezó a elaborar diseños, figuras geométricas y personajes utilizando colores.

Se introdujo el uso de la calculadora del computador para realizar ejercicios simples de las cuatro operaciones matemáticas. 
Figura 75

Escuela El Parvulario de la Fundación EINA

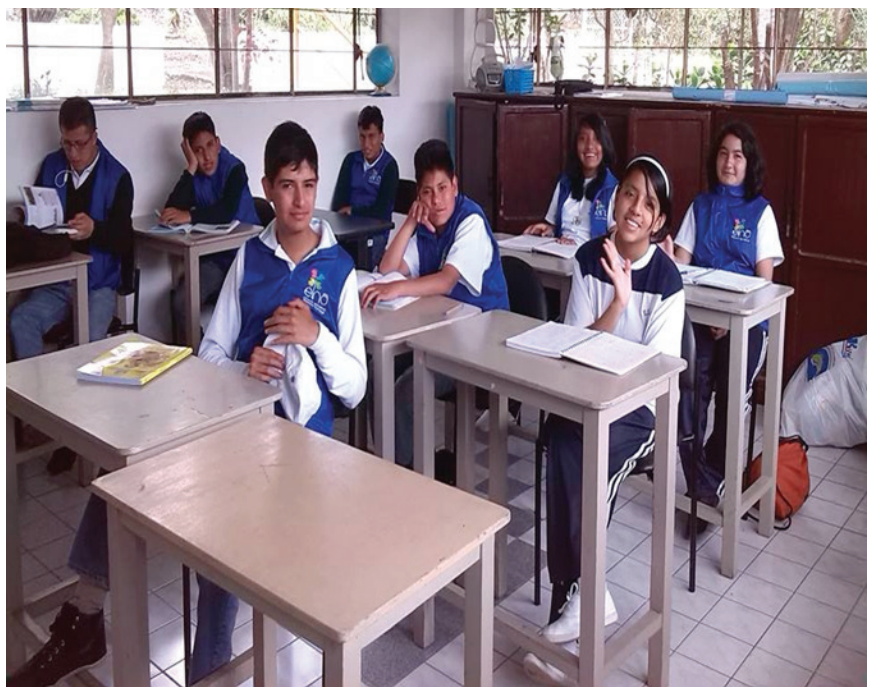

Foto: Silvania Salazar (2016)

\section{Etapa de las operaciones formales}

Edad de 12 años en adelante: la capacidad para utilizar la lógica para llegar a conclusiones abstractas ${ }^{46}$ que no están ligadas a casos concretos que se han experimentado de primera mano.

Jorge Sebastián no alcanza a potenciar el aprendizaje en esta etapa, ya que su nivel de desarrollo intelectual limita el desarrollo de procesos lógicos y abstractos, sin embargo equilibra su aprendizaje con el desarrollo de habilidades mecánicas y funcionales como el uso de la computadora, teléfonos móviles, y redes sociales.

46 El pensamiento abstracto: supone la capacidad de asumir un marco mental de forma voluntaria. Esto implica la posibilidad de cambiar, a voluntad, de una situación a otra, de descomponer el todo en partes y de analizar de forma simultánea distintos aspectos de una misma realidad. 
153

Figura 76

Clase de computación

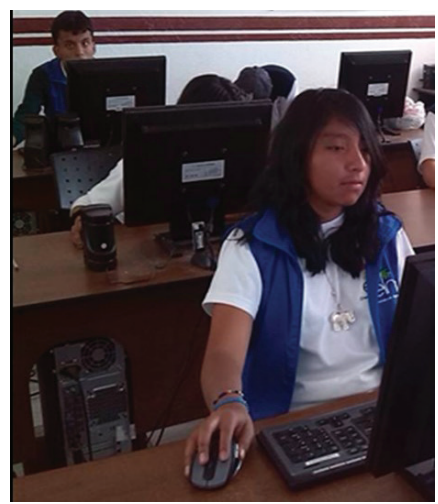

Foto: Silvania Salazar (2016)

Los logros alcanzados por Sebastián en la actualidad son innumerables, la mediación tecnológica recibida le ha permitido alcanzar mayores niveles de autonomía, busca información y prepara presentación sobre temáticas de su interés.

Figura 77

Defensa de tesis

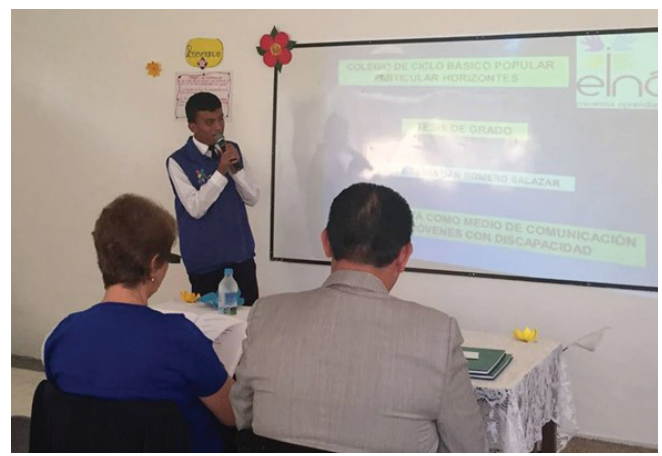

Tema tesis: La danza como medio de comunicación de los jóvenes con discapacidad. Foto: Silvania Salazar (2016) 
154

Luego de revisar la trayectoria educativa de Sebastián se observa que desde tempranas edades tuvo contacto con varios dispositivos tecnológicos.

En el momento actual su madre da testimonio de los logros alcanzados y los resume en los siguientes puntos:

- Le facilitó la adquisición de bases teóricas y destrezas operativas que las utiliza su práctica profesional como Auxiliar de Oficina.

- Sentirse motivado utilizando las herramientas TIC puesto que le permiten aprender las materias de forma más atractiva, amena, divertida, investigando de una forma sencilla.

- Utiliza las TIC en el desempeño diario, personal.

- Utiliza las TIC para mejorar su forma de comunicarse e intercambiar experiencias con los demás enriqueciendo en gran medida su aprendizaje.

Finalmente, considero que hay que buscar las oportunidades de ayuda o de mejora en la educación explorando las posibilidades educativas de la utilización de las TIC en las personas con discapacidad.

Figura 78

Incorporación y presentación de su trabajo académico

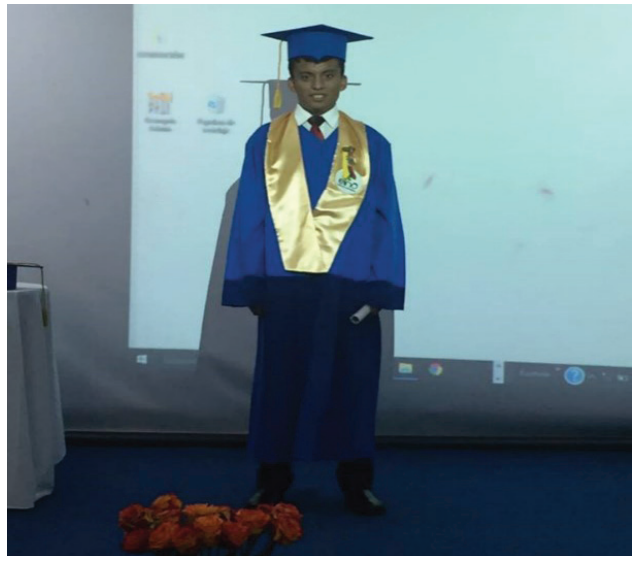

Foto: Silvania Salazar (2016) 
155

Figura 79

Uso de información digital en su entrevista de trabajo

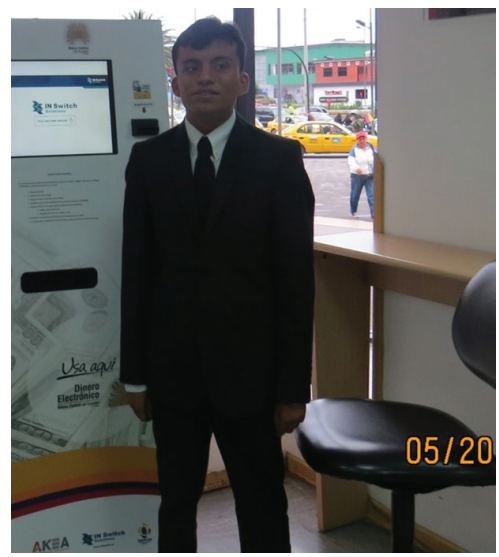

Foto: Silvania Salazar (2016)

\section{Apoyos para garantizar el acceso al aprendizaje de los estudiantes con discapacidad en el nivel superior}

"Los apoyos son recursos y estrategias cuyo objetivo es promover el desarrollo, la educación, los intereses y el bienestar personal de una persona y que mejoran el funcionamiento individual"

(Luckasson)

Universidad Politécnica Salesiana

Ecuador

Quito

Responsable: Mauricio Suárez y Andrés Jaramillo

Gestores de la práctica: Mara Tamayo Directora de la Biblioteca de la UPS

Garantizar la inclusión de estudiantes con discapacidad es un desafío para las instituciones de educación superior. La inclusión educativa tiene que enfocarse en la apropiación de aprendizajes que permitan a los estudiantes alcanzar el perfil de salida planteado para las diferentes carreras, de esta manera en la Universidad Politécnica Salesiana se cuenta con un espacio específico para la adaptación de recursos bibliográficos en formatos accesibles. 